\title{
Violência contra a mulher: um diálogo com estudantes do ensino médio
}

\author{
Ariella Cappellari Nunes ${ }^{1}$, Fernanda Pereira Labiak ${ }^{2}$, \\ Jaqueline Aguiar dos Santos ${ }^{3}$, Melissa Mendes de Novais ${ }^{4}$
}

Resumo: O presente relato de experiência tem como objetivo analisar e socializar uma intervenção de conscientização e de prevenção da violência contra a mulher, promovida por extensionistas do projeto de extensão Direito Intergeracional e Transversalidade da Universidade do Vale do Itajaí em São José (SC), com estudantes do ensino médio de uma escola pública estadual. A partir da atividade de intervenção realizada, que se deu por meio de palestra, puderam ser debatidas com os estudantes questões relacionadas à violência contra mulher, procurando ampliar e entender o conhecimento dos estudantes acerca do tema. Observou-se uma ampla participação dos estudantes, a necessidade de lugar de fala em torno da temática e a autorreflexão em torno das próprias atitudes, comprovando que a educação sobre a violência é uma forma eficiente de prevenção e que a extensão universitária possui papel privilegiado e relevante em promover mudanças culturais e sociais na comunidade e na educação da comunidade acadêmica.

Palavras-chave: Extensão. Violência. Gênero. Ensino médio.

Área Temática: Direitos Humanos, Educação e Gênero.

\section{Violence against women: a dialogue with high school students}

\begin{abstract}
This experience report aims to analyze and socialize an intervention to raise awareness and prevent violence against women, promoted by extensionists of the Intergenerational Law and Transversality Extension Project of the Universidade do Vale do Itajaí in São José (SC), with students. high school from a state public school. From the intervention activity performed, which was given by lecture, could be debated with students issues related to violence against women, seeking to broaden and understand the knowledge of students on the subject. There was a wide participation of students, the need for a place of speech around the theme and self-reflection about their own attitudes, proving that education about violence is an efficient form of prevention and that university extension has a role to play. privileged and relevant in promoting cultural and social changes in the community and in the education of the academic community.
\end{abstract}

Keywords: Extension. Violence. Gender. Highschool.

\footnotetext{
${ }^{1}$ Discente na Universidade do Vale do Itajaí - UNIVALI. E-mail: ariella@edu.univali.br.

${ }^{2}$ Docente na Universidade do Vale do Itajaí - UNIVALI. Coordenadora do Projeto de Extensão Direito Intergeracional e Transversalidade.E-mail: fernanda_labiak@yahoo.com.br.

${ }^{3}$ Discente na Universidade do Vale do Itajaí - UNIVALI. E-mail: jaquesr@ univali.edu.br

${ }^{4}$ Docente na Universidade do Vale do Itajaí - UNIVALI. Coordenadora do Projeto de Extensão Direito Intergeracional e Transversalidade. Rua Vereador Mário Coelho Pires, 341, Apto 901, Campinas São José/SC. (48) 99815-6581. E-mail: melissamendes@univali.br
} 


\section{Violencia contra las mujeres: un diálogo con estudiantes de secundaria}

Resumen: Este informe de experiencia tiene como objetivo analizar y socializar una intervención para crear conciencia y prevenir la violencia contra las mujeres, promovida por los extensionistas del Proyecto de extensión Derecho Intergeneracional y Transversalidad de la Universidade do Vale do Itajaí en São José (SC), con estudiantes de una escuela pública estatal. A partir de la intervención, la actividad realizada, que fue impartida por una conferencia, podría debatirse con los estudiantes sobre cuestiones relacionadas con la violencia contra las mujeres, buscando ampliar y comprender el conocimiento de los estudiantes sobre el tema. Hubo una amplia participación de los estudiantes, la necesidad de un lugar de discurso sobre el tema y la autorreflexión sobre sus propias actitudes, lo que demuestra que la educación sobre la violencia es una forma eficiente de prevención y que la extensión universitaria tiene un papel que desempeñar, privilegiado y relevante en la promoción de cambios culturales y sociales en la comunidad y en la educación de la comunidad académica.

Palabras clave: Extensión. Violencia. Género. Escuela secundaria.

\section{INTRODUÇÃO}

O projeto de extensão Direito Intergeracional e Transversalidade (DIT) do campus Kobrasol, em São José (SC), da Universidade do Vale do Itajaí (Univali) tem buscado, ao longo de 10 anos, promover a troca de conhecimentos, cultura, valores entre a Universidade e o meio em que está inserida, no sentido de contribuir na busca de soluções para os graves problemas sociais da população. No segundo semestre de 2019 foram trabalhadas noções de cidadania e direitos humanos no que tange à violência em decorrência do gênero (violência contra a mulher), bem como o papel da universidade e da escola como espaços privilegiados para promoção de políticas públicas orientadas para a prevenção e enfrentamento desse tipo de violência.

A prevenção e o enfrentamento da violência de gênero estão atrelados, entre tantos aspectos, à construção de uma cidadania mais igualitária para homens e mulheres, em que se desenvolvem ações que priorizem a conscientização acerca dos papéis de gênero como possibilidade de superação da discriminação, da opressão e da exclusão, nas quais é submetido um gênero ao outro. Isso porque, a penalização da violência em si não tem sido suficiente para reduzir os índices de violência contra a mulher, que têm aumentado a cada ano, apesar da criação de tipificações e legislações específicas. A lei Maria da Penha (Lei n $11.340 / 06$ ) ressalta que para além da previsão penal e acolhimento das vítimas, é importante coibir a violência contra a mulher, entre outras formas, pela educação e conscientização.

O enfrentamento da violência pelo viés educacional permite tecer entendimentos e percepções sobre a construção estrutural (sócio-histórica) patriarcal da sociedade, na qual a socialização das pessoas naturaliza e reproduz pensamentos e práticas sexistas, que quando não confrontados e refletidos a fim de trazer criticidade e emancipação do indivíduo, não são superados. A relação entre o saber e o fazer para empreender uma pedagogia emancipadora advém do sentido de práxis, como reflexão e ação dos sujeitos acerca do mundo em prol de transformá-lo (FREIRE, 2005). Nesse sentido, a extensão universitária atua como ferramenta no enfrentamento à violência contra a mulher, ao proporcionar uma interação pedagógica entre universidade e comunidade em torno da desconstrução dos papéis de gênero instituídos socialmente. 


\section{OBJETIVOS}

O presente relato de experiência tem como objetivo analisar e socializar uma intervenção de conscientização e de prevenção da violência contra a mulher, promovida por extensionistas do projeto de extensão DIT, da Univaliem São José (SC), com estudantes do ensino médio de uma escola pública estadual, a fim de oportunizar o empoderamento, a cidadania, a emancipação e a possibilidade de transformação social na vida dos sujeitos envolvidos, enquanto agentes promotores de mudanças.

\section{METODOLOGIA}

A atividade de intervenção realizada se deu por meio de uma palestra-dialogada intitulada "Enfrentamento da violência contra mulher se faz com diálogo também", mediada por acadêmicas do curso de direito participantes do projeto de extensão DIT, orientadas por professoras com formação em psicologia e direito. O públicoparticipante foi de 97 estudantes matriculados do $1^{\circ}$ ao $3^{\circ}$ ano do ensino médio e 3 professores do ensino médio da Escola de Educação Básica Francisco Tolentino, contabilizando 100 pessoas, 54\% do gênero feminino e $46 \%$ do gênero masculino. Esta escola foi escolhida para sediar a referida intervenção por se localizar na região central de São Jose - SC, atender um público com perfil socioeconômico variado e ser próxima da universidade, fazendo parte da comunidade em que está inserida, tendo em vista que a violência contra as mulheres ocorre independentemente de classe socioeconômica, cor ou religião por fazer parte de sistemas estruturais e estruturantes instituídos na sociedade.

A palestra-dialogada foi estruturada de modo a contemplar os objetivos de aprendizagem: apontar e discutir as diversas formas de violência contra a mulher; conscientizar sobre as formas de violência psicológica contra a mulher; problematizar as causas da violência contra mulher; discutir sobre os relacionamentos abusivos; debater o "pornô da vingança"; analisar e avaliar o entendimento dos estudantes sobre as formas de violência contra a mulher. Para avaliar o entendimento do público-participante, bem como a sua percepção em torno da temática proposta e viabilizar às extensionistas mediadoras instrumentos para uma autoavaliação em torno da atividade mediada, foi distribuído ao público-participante um questionário estruturado para quem tivesse interesse em responder de modo voluntário. Foi reservado um tempo médio de 30 minutos para esta avaliação de feedback pedagógico, que teve 05 questões abertas e 02 fechadas, referente às impressões sobre a palestra-dialogada, relevância da temática abordada para si e para a escola, contribuições, sugestões e críticas do público; avaliação que ofereceu subsídios práticos para a sistematização deste relato de experiência.

\section{RESULTADOS E DISCUSSÃO}

As respostas do público-participante no questionário estruturado de cunho avaliativo à intervenção feita foram sintetizadas para compor este relato de experiência. A estratégia utilizada para compilar os dados para a 
análise foi Análise de Conteúdo de Bardin (2011). Das 100 pessoas presentes, 52 se dispuseram a responder voluntariamente o questionário e a partir das respostas, as categorias de análise foram geradas: a) o que você achou da palestra e por quê?; b) você acha que algo poderia ter sido diferente? Tem alguma sugestão de melhoria? e; c) satisfação geral sobre a atividade realizada.

Na categoria A - “o que você achou da palestra e por quê?” foram computadas diversas respostas, entre elas: "bom, me ensinou coisas que eu não sabia e fez mudar algumas coisas que pensava" [sic]; "bom, foi útil, me fez saber o que é um relacionamento abusivo e que machismo não é unilateral” [sic]; “bom, elas [palestrantes] comentaram sobre algo que aconteceno dia a dia, fiquei com aimpressão que eu podia fazer mais”" [sic]; "ótimo, porque conscientizou e abriu uma plataforma de debates"[sic]; “ótimo, porque me ajudou a saber os tipos de agressão e como cortar o mal pela raiz" [sic]. As respostas demonstram a concretização prática dos objetivos da palestra-dialogada não só em termos de assimilação do conteúdo, como na transcendência deste conteúdo para o cotidiano. Por meio das opiniões expressas, os participantes demonstraram ter sido sensibilizados pelo conteúdo trabalhado no sentido de se colocar como sujeito social responsável por suas ações e que suas ações são determinantes para a perpetuação das violências.

Na categoria A, fomenta-se a análise da resposta “ótimo, tudo origina de uma cultura machista, devemos começar a mudança aos poucos em nossas casas e grupos sociais" [sic]. Diante do exposto, é possível perceber o elemento salutar do enfrentamento à violência contra mulher, que é o reconhecimento individual como parte do problema, não necessariamente como vítima ou agressor direto, mas como pessoa socializada, desde o berço, em uma cultura que fomenta diariamente a violência de gênero. Destaca-se, portanto, que assinalar a importância do reconhecimento individual do problema não diminui a centralidade das transformações estruturais que produzem as violências de gênero, raça, classe, sexualidade, entre outras formas, sendo necessário, também, que esse reconhecimento individual se expanda, através de práticas e diálogos, a fim de se tornar reconhecimento social, capaz de transformar o cerne da legitimação social da violência de gênero, qual seja a cultura patriarcal e heteronormativa.

"Não gostei de ver na palestra o número de estupros. Percebi que eu era um agressor em vários relacionamentos que tive" [sic]. Esta resposta, analisada na categoria A, expressa uma autorreflexão em que o autor se reconhece como agressor e, por assim dizer, usando o verbo no passado - "era"-infere a abertura para mudar as próprias práticas. Aspecto quemostra a eficácia da prevenção por meio da promoção do diálogo, da construção de conhecimento e da conscientização de práticas culturais violentas. Confrontar práticas sexistas é fundamental no enfrentamento da violência contra a mulher.

"Péssima, pois influência as mulheres ficarem contra os homens e faz com que elas achem que todos os homens são assim agressivos. Não indicaria esta palestra. Este assunto é muito abordado toda hora e já tá chato" [sic]; resposta elencada na categoria A e que suscita o questionamento: por que é importante falar sobre a violência contra as mulheres? Vale destacar que as mulheres são vítimas de violências diversas pelo fato de serem 
mulheres. Logo, os índices de violência são alarmantes, no Brasil, em 2017, 4.936 mulheres foram mortas, totalizando uma média de 13 assassinatos por dia. Entre 2007-2017 houve um aumento de 30,7\% no número de homicídios de mulheres ${ }^{1}$ no país (IPEA, 2019). Em 2018 o Brasil registrou 263.067 casos de violência doméstica e 66.041 casos de violência sexual, dos quais $81,8 \%$ das vítimas eram mulheres (FBSP, 2019). Estes números abordam os casos em que houve registro de denúncia e, portanto, os números reais são ainda maiores.

Na categoria B -"você acha que algo poderia ter sido diferente? Tem alguma sugestão de melhoria?", obtevese respostas como: "sim, uma interação maior e mais tempo para o público falar"' [sic]; "não, os assuntos estão no rumo certo, faltou mais interação" [sic]. Conforme as respostas elencadas, foi notado que o público-participante sentiu falta de um tempo maior para que pudessem se expressar e haver mais interação. Enfatiza-se, desse modo, a necessidade de estabelecer diálogos sobre a violência de gênero, pois há muito a ser explorado nesse âmbito. O público-participante está reivindicando espaços de fala e de escuta, quer debater o assunto abertamente, fato que confirma a necessidade de ampliar entendimentos e percepções sobre a segurança e a integridade física, psicológica, patrimonial da mulher e a caminhada rumo à equidade de gênero. Isso vem ao encontro dos apontamentos de Freire (2013, p. 107) sobre aextensão enquanto comunicação em que o processo de emancipação pressupõe autonomia, pois ninguém liberta ninguém, portanto, "educador-educando e educando-educador, no processo educativo libertador, são ambos sujeitos cognoscentes diante de objetos cognoscíveis, que os mediatizam".

Na categoria C - "satisfação geral sobre a atividade realizada", 60\% do público-participante classificou a palestra-dialogada como ótima, $28 \%$ como boa, $9 \%$ como regular e $3 \%$ como péssima. Analisa-se diante desses dados que o impacto social é imensurável ao tecer entendimentos e percepções sobre a violência de gênero (violência contra a mulher), isso porque o público-participante está munido de conhecimento e, possivelmente, as discussões propostas vão reverberar, possibilitando um (re)significar das suas construções sociais dentro de seus círculos de amizades, familiares, entre outros.

O projeto de extensão comprovou sua importância acadêmica e social, colaborando com seu conceito de fazer com que os extensionistas não simplesmente estendam seus conhecimentos e suas técnicas e sim compreendam o processo educativo como uma situação gnosiológica, assim, se apresentando como uma ferramenta valiosa de interação com a comunidade, além de proporcionar aos estudantes da graduação a experiência de pensar uma prática pedagógica libertária. A comunidade é colocada, nessa perspectiva, não como objeto, mas como sujeito capaz de transformar a realidade de todas as pessoas envolvidas do processo pedagógico (FREIRE, 2013).

No tocante às perspectivas das extensionistas-acadêmicasem relação à atividade realizada, salientam que puderam vivenciar o caráter dialógico da extensão em que por meio da intervenção desenvolvida pôde ser partilhado, de ambos os lados (universidade - comunidade), saberes e reflexões sem manipulação ou invasão do contexto apresentado, uma vez que a promoção do diálogo se deu num processo de troca. Ao articularem os conhecimentos oriundos do curso de graduação e as concepções teóricas desenvolvidas no projeto de extensão 
DIT para intervir na comunidade, foram capazes de avaliar situações/contextos abrangentes da violência de gênero de forma crítica e reflexiva, produzindo estratégias de interação com a comunidade, levando em consideração a especificidade do público-participante, a fim de construir soluções/conhecimentos que atendam uma das demandas crescentes e urgentes da sociedade que é dirimir a violência contra mulher. À vista disso, avaliaram que competências como pensamento crítico, capacidade de reflexão e autonomia foram desenvolvidas.

\section{CONCLUSÕES}

Diante do exposto, fica claro que a sociedade carece de diálogos sobre a violência de gênero e que há muito a ser explorado nesse âmbito. Pôde-se notar o potencial da educação em torno das questões de gênero como forma preventiva da violência em face do caráter punitivista, fato relevante, uma vez que a prevenção evita que haja qualquer tipo de vítima, enquanto a punição pode apenas interferir de modo paliativo, evitando, temporariamente, que haja novas vítimas da violência em decorrência do gênero. Ademais, não se pode desconsiderar que o próprio sistema penal e seu caráter seletivo, reforça outras dimensões de violência que também devem ser contestadas.

A construção de saberes aqui relatados fez-se de forma colaborativa e, ao mesmo tempo, autônoma, no sentido em que existiu uma construção de conhecimento que foi feita diante - e apenas diante - da troca de experiências e vivências, fugindo da curva de um processo de ensino-aprendizagem em que um fala e outro passivamente absorve. Ainda, os indivíduos envolvidos tiveram a oportunidade de aprendizagem para além dos manuais, baseada na vivência prática. Assim, resta salientar o papel da extensão para uma educação emancipatória, tanto das/os extensionistas da universidade, quanto para as/os extensionistas da comunidade, visto que ao abrir um amplo diálogo, possibilita uma construção e ressignificação de saberes.

\section{Notas:}

${ }^{1}$ O Relatório do Atlas da violência refere-se a homicídios femininos como categoria mais ampla em relação ao feminicídio, o qual constitui circunstância qualificadora do crime de homicídio. Por se tratar de um tipo penal recente (Lei no 13.104/2015), o relatório considera a possibilidade de subnotificação entre outras razões para a escassez de dados que apontem a sua real dimensão no país.

\section{REFERÊNCIAS}

BARDIN, L. Análise de conteúdo. São Paulo: Edições 70, 2011.

BRASIL. Lei 11.340, de 07 de agosto de 2006. Cria mecanismos para coibir a violência doméstica e familiar contra a mulher, [...] Presidência da República, Casa Civil, Subchefia para assuntos jurídicos. DF, 07 ago. 2006.

FÓRUM BRASILEIRO DE SEGURANÇA PÚBLICA(FBSP). Anuário brasileiro de segurança pública: 2019. São Paulo: FBSP, 2019. Disponível em: <http://www.forumseguranca.org.br/wp-content/uploads/2019/ 10/Anuario-2019-FINAL_21.10.19.pdf>. Acesso em: 10 Jun. 2020. 


\section{INSTITUTO DE POLÍTICA ECONÔMICAAPLICADA(IPEA); FÓRUM BRASILEIRO DE}

SEGURANÇA PÚBLICA (FBSP). Atlas da violência 2019. São Paulo; Rio de Janeiro, 2019. Disponível em: <http://www.ipea.gov.br/portal/index.php?option=com_content\&view=article\&id=34784\&Ite mid=432>. Acesso em: 10 Jun. 2020.

FREIRE, P. Extensão ou comunicação. 19. ed. São Paulo: Paz e Terra, 2013.

FREIRE, P. Pedagogia do oprimido. Rio de Janeiro: Paz e Terra, 2005.

Submetido em: 19/12/2019 Aceito em: 03/06/2020. 